\title{
Assessment of Implant Stability Changes and Success Rate of Narrow Dental Implants
}

\author{
${ }^{1}$ Athraa A Alsheikhly, ${ }^{2}$ Salwan Y Bede
}

\section{ABSTRACT}

Aims: To assess the success rate and implant stability changes of narrow dental implants (NDIs) during the osseous healing period.

Materials and methods: This prospective observational clinical study included 21 patients with narrow alveolar ridge of restricted mesiodistal interdental span who received NDIs. The alveolar ridge width was determined by the ridge mapping technique. Implant stability was measured using Periotest $₫ \mathrm{M}$ immediately after implant insertion then after 4 weeks, 8 weeks and 12 weeks postoperatively. The outcome variables were success rate and implant stability changes during the healing period. The statistical analysis included one-way analysis of variance (ANOVA) and Tukey's multiple comparisons test, values $<0.05$ were considered statistically significant.

Results: Twenty-one patients received 54 implants, the success rate was $92.6 \%(50 / 54)$. The mean \pm SD periotest value (PTV) was significantly increased at 4 weeks (7.62 \pm 6.39 PTV) compared with primary stability $(1.48 \pm 3.16$ PTV), at 8 weeks $(4.46 \pm 4.45 \mathrm{PTV})$. It significantly decreased compared with that at 4 weeks and at 12 weeks (1.82 \pm 3.22 PTV); it decreased significantly compared to that at 8 weeks.

Conclusion: Narrow dental implants have a high early success rate. The implant stability during the healing period drops significantly in the first 4 weeks postoperatively and then increases steadily in the following weeks to reach to a level close to that of primary stability after 12 weeks.

Clinical significance: Narrow dental implants are indicated in cases of insufficient alveolar bone width obviating the need for bone augmentation and reduced interdental space such as in cases of congenitally missing teeth or after orthodontic treatment. Knowledge of the stability changes during the osseous healing period enables the clinicians to determine the optimum time for functional loading.

Keywords: Implant stability, Narrow alveolar ridge, Narrow dental implant.

How to cite this article: Alsheikhly AA, Bede SY. Assessment of Implant Stability Changes and Success Rate of Narrow Dental Implants. World J Dent 2019;10(1):18-22.

\footnotetext{
1,2Department of Oral and Maxillofacial Surgery, College of Dentistry, University of Baghdad, Bab-Almoadham, Medical City, Baghdad, Republic of Iraq

Corresponding Author: Salwan Y Bede, Department of Oral and Maxillofacial Surgery, College of Dentistry, University of Baghdad, Bab-Almoadham, Medical City, Baghdad, Republic of Iraq, Phone: 009647906210006, e-mail:salwan.bede@gmail. com, salwan.bede@codental.uobaghdad.edu.iq
}

\section{Source of support: Nil}

\section{Conflict of interest: None}

\section{INTRODUCTION}

Alveolar bone atrophy often presents a significant obstacle to achieving successful oral rehabilitation with endosseous implants, it is suggested that a minimum thickness of 1-1.5 mm of bone should remain on both buccal and lingual/palatal aspects of implants to ensure a successful outcome. ${ }^{1}$

Several advanced surgical techniques have been reported to augment horizontal dimension, such as osteotomies, ${ }^{2}$ crestal expansion techniques, ${ }^{3}$ autogenous bone, ${ }^{4}$ guided bone regeneration (GBR), ${ }^{5}$ and distraction osteogenesis, ${ }^{6}$ these procedures offer good results in implantology, but they are not without complications, ${ }^{7}$ the associated inconveniences are increased morbidity, longer healing times, and infection secondary to wound dehiscence or membrane exposure. ${ }^{8}$

In patients with deficient crest width, the utilization of narrow dental implants (NDIs) constitutes a technical treatment alternative, they have been approved for longterm use in 1997 by the FDA. The main indications of NDIs are insufficient alveolar bone width obviating the need for bone augmentation ${ }^{9}$ and reduced interdental space such as in cases of congenitally missing teeth or after orthodontic treatment. ${ }^{10}$ Narrow dental implants are one piece titanium screw with a ball-shaped head for denture stabilization or square prosthetic head for fixed applications, and they protrude over the gum surface when they are placed into the bone. ${ }^{11}$

Implant stability is an essential condition for the successful clinical outcome of implants; it can be defined as the capacity to withstand loading from axial, lateral, and rotational directions. ${ }^{12,13}$ Primary stability mostly occurs from mechanical attachment with cortical bone, whereas secondary stability offers biological stability through bone regeneration and remodeling. ${ }^{14}$

To the authors' knowledge, there are no studies that assess NDIs stability changes during the osseous healing period; therefore, this study aimed to assess the stability changes of NDIs immediately after insertion (primary stability) and after at 4 weeks, 8 weeks and 12 weeks (secondary stability) postoperatively and their success rate. 


\section{MATERIALS AND METHODS}

This prospective observational clinical study included 21 patients, who attended the Department of Oral and Maxillofacial Surgery at the College of Dentistry, University of Baghdad, for dental implant treatment of missing teeth during the period extending from November 2017 to November 2018.

The inclusion criteria were medically fit patients $\geq 18$ years of age including both genders presenting with narrow alveolar ridges (3-4 $\mathrm{mm}$ ) or restricted mesiodistal interdental span and adequate vertical bone height. Patients were excluded from the study when they had signs of infection in the proposed implant zone, parafunctional habits such as severe bruxism and clenching, or local limitations such as inadequate inter-ridge distance or insufficient vertical bone height.

The study was approved by the institutional review board, and every patient was informed about the procedures and the nature of the study, and those who agreed to participate signed informed consent.

The ridge width of the proposed implant site was determined by the ridge mapping technique described by Wilson in $1989,{ }^{15}$ using bone caliper after administration of local anesthesia, two measurements were taken at each implant site; at $3 \mathrm{~mm}$ and $6 \mathrm{~mm}$ from the crest of the ridge.

A three-sided mucoperiosteal flap was reflected to expose the alveolar bone. The implant site preparation and installation of the NDIs (SlimLine, Dentium Co., Ltd., Korea) proceeded as per the manufacturer instructions. The drilling was performed at a speed of 600-800 rpm and torque of $35 \mathrm{~N} / \mathrm{cm}$ under copious irrigation. Bone quality was determined subjectively by cutting torque perceived by the operator and classified into one of four types of bone quality (types 1 to 4 ). According to Lekholm and Zarb, ${ }^{16}$ the implants were installed using a rotary method (Fig. 1) set at $50 \mathrm{rpm}$ and torque of $35 \mathrm{~N} / \mathrm{cm}$; The

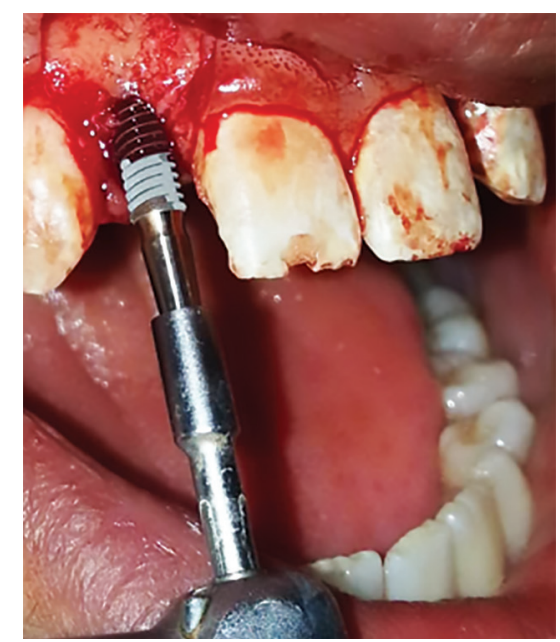

Fig. 1: A clinical view showing installation of dental implant by rotary method final seating was achieved with manual driver or ratchet. After implant placement, primary stability was measured using Periotest ${ }^{\circledR} \mathrm{M}$ (Medizintechnik Gulden, Germany) (Fig. 2), two repeated measurements were obtained for each implant and the mean of these two readings was recorded as a Periotest value (PTV).

Patients were instructed for follow up visits at 4 weeks, 8 weeks and 12 weeks postoperatively in which implant stability was measured using Periotest ${ }^{\circledR} \mathrm{M}$ in the same manner described in primary stability measurement. The implant stability measured at the 12 th week was considered as the secondary stability. The patients were referred for final prosthesis construction after the end of the follow-up period (12 weeks).

The outcome variables in this study included the implant stability immediately after insertion (primary stability), at 4 weeks, 8 weeks and 12 weeks (secondary stability) postoperatively to determine the pattern of implant stability changes, and the success rate of dental implants; success was defined as implants that were clinically stable, pain free with no exudates after 12 weeks postoperatively. ${ }^{17}$

Descriptive statistical analysis included calculation of mean \pm standard deviation (SD) and inferential analysis included using one-way analysis of variance ANOVA and Tukey's multiple comparisons test, values $<0.05$ were considered statistically significant.

\section{RESULTS}

Twenty-one patients with a mean age $( \pm$ SD) of $40.8( \pm 16.7)$ years participated in this study, and they consisted of 9 males (42.9\%) and 12 females (57.1\%). The mean width of the alveolar ridge measured by ridge mapping was $0.3( \pm$ $0.7) \mathrm{mm}$ at $3 \mathrm{~mm}$ from the crest of the ridge (range $0-4 \mathrm{~mm}$ ) and $3.8( \pm 0.9) \mathrm{mm}$ at $6 \mathrm{~mm}$ from the crest of the ridge (range $=2-5 \mathrm{~mm}$ ).

The patients received 54 NDIs; 44 implants were inserted in 16 patients who had a narrow alveolar ridge, and 10 implants were placed in 5 patients who had restricted mesiodistal interdental distance. Thirty implants (55.6\%) were inserted in the maxilla; 24 in the anterior region and 6 in the posterior region, and 24 implants (44.4\%)

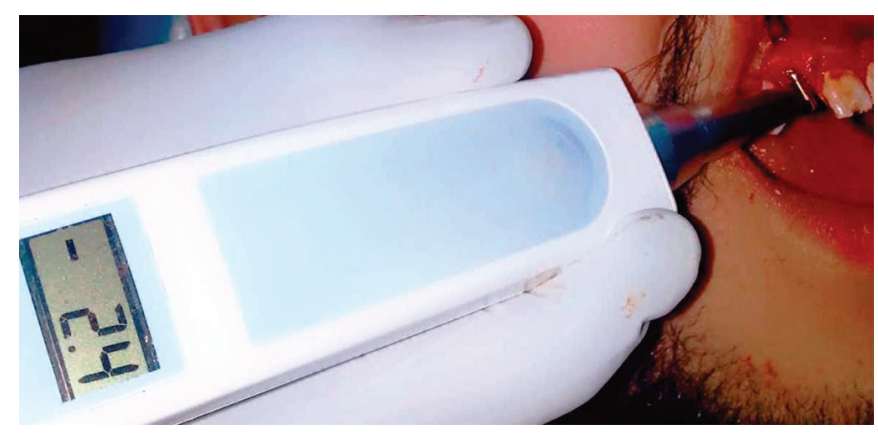

Fig.2: A clinical view of measuring primary implant stability using Periotest ${ }^{\circledR}$ M (Medizintechnik Gulden, Germany) 
Table 1: Distribution of dental implants according to diameter and length

\begin{tabular}{|c|c|c|c|c|}
\hline \multirow[b]{2}{*}{ Implant diameter/mm } & \multicolumn{3}{|c|}{ Implant length $(\mathrm{mm})$} & \multirow[b]{2}{*}{ Total (\%) } \\
\hline & 8 & 10 & 12 & \\
\hline 2.0 & 1 & 3 & 2 & $6(11.1)$ \\
\hline 2.5 & 1 & 9 & 15 & $25(46.3)$ \\
\hline 3.0 & 2 & 11 & 10 & $23(42.6)$ \\
\hline Total (\%) & $4(7.4)$ & $23(42.6)$ & $27(50)$ & $54(100)$ \\
\hline
\end{tabular}

Table 2: Types of bone quality

\begin{tabular}{ll}
\hline Bone type & Number $(\%)$ \\
\hline Type 1 & $12(22.2)$ \\
Type 2 & $18(33.3)$ \\
Type 3 & $19(35.2)$ \\
Type 4 & $5(9.3)$ \\
\hline Total & $54(100)$ \\
\hline
\end{tabular}

were installed in the mandible; 14 in the anterior region and 10 in the posterior region. The length and width of the dental implants used in this study are shown in Table 1. The most frequent types of alveolar bone quality encountered in this study were types 3 and 2 (Table 2).

At the end of the healing period, 50 implants were stable and successfully osseointegrated and fulfilled the criteria of success producing survival rate of $92.6 \%$. Four implants failed during the first follow-up period (4 weeks); implant failure was encountered in 3 cases with type 1 bone quality and 1 case with type 4 bone quality.

The mean PTV $( \pm$ SD) of the successful dental implants $(n=50)$ significantly increased at 4 weeks compared with that at the implant insertion, at 8 weeks it decreased significantly compared with the measurements at 4 weeks and at the end of the follow-up period (at 12 weeks), the mean PTV decreased significantly compared with that at 8 weeks. The difference between the mean PTV at surgery and at 12 weeks was statistically non-significant (Table 3 ).

\section{DISCUSSION}

This study aimed to assess the success rate and implant stability changes during the healing period of NDIs inserted in a narrow alveolar ridge or cases of restricted interdental space.

The ridge mapping technique has been reported in the literature to be a reliable and convenient method to assess the alveolar ridge width and the suitability of potential implant sites. ${ }^{15,18-20}$

Quantitative methods including resonance frequency analysis can yield valuable information to measure implant stability. ${ }^{21}$ Periotest $^{\circledR} \mathrm{M}$ was used in this study because of the single body design of NDIs which precludes connecting a transducer and using resonance frequency analyzer. Oh et al..$^{22}$ found that Periotest ${ }^{\circledR}$ was as reliable as resonance frequency analysis in measuring implant stability and they reported no difference between the two methods.

Dental implant stability measurement during the healing period demonstrated a significant decrease in stability after 4 weeks compared to primary stability followed by a significant increase at 8 weeks postoperatively. This pattern of implant stability changes during the healing period is supported by other studies that observed a reduction in implant stability 3-4 weeks after implant insertion followed by improvement in stability in the following weeks, this stability reduction corresponds with the bone remodeling process marked by bone resorption stage that takes place during the early period after implant insertion. ${ }^{23,24}$

Other studies, however, found that implant stability either remains constant or even increases during the early weeks after implant insertion. ${ }^{25,26}$ At 12 weeks the implant stability increased to become close to that of primary sta-

Table 3: Summary of the differences in mean implant stability at 4 time intervals

\begin{tabular}{lll}
\hline Implant stability & Mean $( \pm S D) / P T V s$ & $p$ value \\
\hline Primary stability & $1.48( \pm 3.16)$ & $0.0001(\mathrm{~S})^{\mathrm{a}}$ \\
At 4 weeks & $7.62( \pm 6.39)$ & \\
At 8 weeks & $4.46( \pm 4.45)$ & $1.82( \pm 3.22)$ \\
At 12 weeks (secondary stability) & Mean difference/ PTV & $p \leq 0.0001(\mathrm{~S})^{\mathrm{b}}$ \\
The difference in implant stability & 6.14 & $\mathrm{p} \leq 0.0001(\mathrm{~S})^{\mathrm{b}}$ \\
Between implant stability at 4 weeks and primary stability & -3.16 & $\mathrm{p} \leq 0.0001(\mathrm{~S})^{\mathrm{b}}$ \\
Between implant stability at 4 weeks and at 8 weeks & -2.64 & $\mathrm{p}>0.05(\mathrm{~N} . \mathrm{S})^{\mathrm{b}}$ \\
Between implant stability at 8 weeks and at 12 weeks & 0.34 & \\
Between the stability at 12 weeks and the primary stability & & \\
\hline${ }^{\mathrm{a} O n e-w a y ~ A N O V A ~ f o r ~ r e p e a t e d ~ m e a s u r e s ~}$ & & \\
${ }^{\mathrm{b} T u k e y ' s ~ m u l t i p l e ~ c o m p a r i s o n s ~ t e s t ~}$ & & \\
S significant & & \\
NS nonsignificant & & \\
PTV periotest value & & \\
\hline
\end{tabular}


bility which is in keeping with other studies. ${ }^{27,28}$ To note, all the aforementioned studies addressed the implant stability changes in implant diameter ranging from 3.3 to $4.8 \mathrm{~mm}$ which is larger than that presented in this study.

Low PTVs indicate high stability while high values indicate low implant stability. Meredith ${ }^{21}$ reported that implants that reached a value of -5 to +5 PTVs had a sufficient level of stability. Bilhan et al. ${ }^{29}$ suggested that positive values should alert the clinicians to take additional precautions such as unloading until implant stability is regained or check for trauma or infection.

Studies assessing NDIs have reported implant success and survival rates similar to those obtained with larger diameterimplants.Sierra-Sánchezetal. ${ }^{30}$ and Sohrabietal. ${ }^{31}$ concluded that NDIs represented a predictable treatment option with clinical outcome and survival rate that was similar to regular implants. According to the results of this study, the early success rate obtained was $92.6 \%$, many authors reported that the survival rate of implants with a diameter of $<3 \mathrm{~mm}$ was higher than $90 \%$ with a follow-up time between 1 year and 11 years. ${ }^{32-35}$

Four implants (7.4\%) were lost during the first 4 weeks; three of which were inserted in type 1 bone quality. This bone type is almost all cortical and the capacity of regeneration is impaired because of the poor blood supply. ${ }^{36}$ Some studies such as Alsaadi et al. in $2007^{37}$ suggested that type 1 bone was more likely to cause failure in implant treatment, while Turkyilmaz and McGlumphy ${ }^{38}$ reported better success rate in type 1 bone.

This study is limited in its observational design, small sample size and short follow-up period that does not include a long-term assessment of the implant success or complications after the fabrication of the prostheses and functional loading.

\section{CONCLUSION}

Narrow diameter implants are indicated in cases of narrow alveolar ridges and restricted mesiodistal distance with high early success rate. During the healing period, implant stability drops significantly in the first 4 weeks postoperatively and then increases steadily in the following weeks to reach a level close to that of primary stability after 12 weeks.

\section{CLINICAL SIGNIFICANCE}

Narrow dental implants are indicated in cases of insufficient alveolar bone width obviating the need for bone augmentation and reduced interdental space such as in cases of congenitally missing teeth or after orthodontic treatment. Knowledge of the stability changes during the osseous healing period enables the clinicians to determine the optimum time for functional loading.

\section{REFERENCES}

1. Scipioni A, Bruschi GB, Calesini G, Bruschi E, De Martino C. Bone regeneration in the edentulous ridge expansion technique: Histologic and ultrastructural study of 20 clinical cases. Int J Periodontics Restorative Dent 1999;19:269-277.

2. Summers R.B. A new concept in maxilary Implant surgery: the osteotome technique. Compendium 1994;15:152-158.

3. Scipioni A, Bruschi GB, Calesini G. The edentulous ridge expansion technique: a five-year study. Int J Periodontics Restor Dent 1994;14:451-459.

4. Dahlin C, Johansson A. Iliac crest autogenous bone graft versus alloplastic graft and guided bone regeneration in the reconstruction of atrophic maxillae: a 5-year retrospective study on cost-effectiveness and clinical outcome. Clin Implant Dent Relat Res 2011;13: 305-310.

5. Hammerle $\mathrm{CH}$, Jung RE, Feloutzis A. A systematic review of the survival of implants in bone sites augmented with barrier membranes (guided bone regeneration) in partially edentulous patients. J ClinPeriodontol 2002;29 Suppl 3:226-31;discussion 232-233.

6. Braidy H, Appelbaum M. Alveolar distraction osteogenesis of the severely atrophic anterior maxilla: surgical and prosthetic challenges. J Prosthodont 2011;20:139-143.

7. Grunder U, Wenz B, Schupbach P. Guided bone regeneration around single-tooth implants in the esthetic zone: a case series. Int J Periodont Res 2011;31:613-620.

8. Esposito M, Grusovin M.G, Felice P, Karatzopoulos G, Worthington HV, Coulthard P. The efficacy of horizontal and vertical bone augmentation procedures for dental implants: a Cochrane systematic review. Eur J Oral Implantol 2009;2: 167-184.

9. Davarpanah M, Martinez H, Tecucianu JF, Celletti R, Lazzara R. Small-diameter implants: indications and contraindications. J Esthet Dent. 2000; 12(4):186-194.

10. Froum SJ, Cho SC, Cho YS, et al. Narrow-diameter implants: a restorative option for limited interdental space. Int J Periodont Rest Dent 2007;27:449-455.

11. Gleiznys A, Skirbutis G, Harb A, Barzdziukaite I, Grinyte I. New approach towards mini dental implants and smalldiameter implants: an option for long- term prosthesis. Stomatologi J 2012;14(2):39-45.

12. Sennerby L, Meredith N. Implant stability measurements using resonance frequency analysis: biological and biomechanical aspects and clinical implications. Periodontol 2000 2008;47:51-66.

13. Östman PO, Hellman M, Wendelhag I, Sennerby L. Resonance frequency analysis measurements of implants at placement surgery. Int J Prosthodont 2006;19:77-83.

14. Sennerby L, Roos J. surgical determinants of clinical success of osseointegrated oral implants. A review of literature. Int J Prosthodont 1998;11:408-420.

15. Wilson, D.J. Ridge mapping for determination of alveolar ridge width. Int J Oral Maxillofac Implants 1989;4:41-43.

16. Lekholm U, Zarb GA. Patient selection and preparation. In Tissue-integrated prostheses: osseointegration in clinical dentistry. Branemark P-1, Zarb GA, Albrektsson T. (eds.) Quintessence; 1985. p. 199-209.

17. Misch CE, Perel ML, Wang HL, Sammartino G, GalindoMoreno P, Trisi P, et al. Implant success, survival, and failure: the International Congress of Oral Implantologists (ICOI) Pisa Consensus Conference. Implant Dent 2008;17(1):5-15. 
18. Traxler, M., Ulm, C., Solar, P. \& Lill, W. Sonographic measurement versus mapping for determination of residual ridge width. J Prosthet Dent 1992;67:358-361.

19. Ten Bruggenkate CM, de Rijcke TB, Kraaijenhagen HA, Oosterbeek HS. Ridge mapping. Implant Dent 1994;3: 179-182.

20. Chen LC, Lundgren T, Hallström H, Cherel F. Comparison of different methods of assessing alveolar ridge dimensions prior to dental implant placement. J Periodontol 2008;79: 401-405.

21. Meredith N. Assessment of implant stability as a prognostic determinant. Int J Prosthodont 1998;11:491-501.

22. Oh JS, Kim SG, Lim SC, Ong JL. A comparative study of two noninvasive techniques to evaluate implant stability: Periotest and Osstell Mentor. Oral Surg Oral Med Oral Pathol Oral RadiolEndod 2009;107:513-518

23. Han J, Lulic M, Lang NP. Factors influencing resonance frequency analysis assessed by Osstellt mentor during implant tissue integration: II. Implant surface modifications and implant diameter. Clin Oral Implants Res 2010;21(6):605-611.

24. Boronat-Lopez A, Balaguer-Martinez J, Lamas-Pelayo J, Carrillo Garcia C, PenarrochaDiago M. Resonance frequency analysis of dental implant stability during the healing period. Med Oral Patol Oral Cir Bucal 2008;13(4):244-247.

25. Huwiler MA, Pjetursson BE, Bosshardt DD, Salvi GE, Lang NP. Resonance frequency analysis in relation to jawbone characteristics and during early healing of implant installation. Clin Oral Implants Res 2007;18:275-280.

26. Bischof M, Nedir R, Szmukler-Moncler S, Bernard JP, Samson J. Implant stability measurement of delayed and immediately loaded implants during healing. Clin Oral Implants Res 2004;15:529-539.

27. Valderrama P, Oates TW, Jones AA, Simpson J, Schoolfield JD, Cochran DL. Evaluation of two different resonance frequency devices to detect implant stability: a clinical trial. J Periodont 2007; 78(2):262-272.

28. Balshi SF, Allen FD, Wolfinger GJ, Balshi TJ. A resonance frequency analysis assessment of maxillary and mandibular immediately loaded implants. Int J Oral Maxillofac Implants 2005;20(4): 584-594.

29. Bilhan H, Cilingir A, Bural C, Bilmenoglu C, Sakar O, Geckili $\mathrm{O}$. The evaluation of the reliability of periotest for implant stability measurements: an in vitro study. J Oral Implantol 2015;41(4):90-95.

30. Sierra-Sánchez JL, Martínez-González A, García-SalaBonmatí F, Mañes Ferrer JF, Brotons-Oliver A.Narrow-diameter implants: Are they a predictable treatment option? A literature review. Med Oral Patol Oral Cir Bucal. 2014;19(1):e74-81.

31. Sohrabi K, Mushantat A, Esfandiari S, Feine J. How successful are small-diameter implants? A literature review. Clin Oral Impl Res 2012;23:515-525.

32. El-Sheikh AM, Shihabuddin OF, Ghoraba SM. Two versus three narrow-diameter implants with locator attachments supporting mandibular overdentures: a two-year prospective study. Int J Dent. 2012;2012:285684.

33. Maló $\mathrm{P}$, de Araújo Nobre M. Implants ( $3.3 \mathrm{~mm}$ diameter) for the rehabilitation of edentulous posterior regions: a retrospective clinical study with up to 11 years of follow-up. Clin Implant Dent Relat Res 2011;13:95-103.

34. Arisan V, Bölükbasi N, Ersanli S, Özdemir T. Evaluation of 316 narrow diameter implants followed for 5-10 years: a clinical and radiographic retrospective study. Clin Oral Impl Res 2010;21:296-307.

35. Degidi M, Nardi D, Piatelli A. Immediate restoration of smalldiameter implants in cases of partial posterior edentulism: a 4-year case series. J. Periodontol 2009;6:1006-1012.

36. Misch CE. Density of Bone: Effects on surgical approach and healing. In: Misch CE. editor. Contemporary Implant Dentistry. 3rd edition. St. Louis: Mosby Elsevier; 2008. p. 645-667

37. Alsaadi G, Quirynen M, Komarek A, Van Steenberghe D. Impact of local and systemic factors on the incidence of oral implant failures, up to abutment connection. J ClinPeriodontol 2007;34(7):610-617.

38. Turkyilmaz I, McGlumphy EA. Influence of bone density on implant stability parameters and implant success: a retrospective clinical study. BMC Oral Health 2008;8(1):32. 